\title{
Experimental animal models for moyamoya disease and treatment: a pathogenesis-oriented scoping review
}

\author{
*Michael S. Rallo, BS, Omar Akel, MBS, Akhilesh Gurram, and Hai Sun, MD, PhD \\ Department of Neurosurgery, Rutgers Robert Wood Johnson Medical School, New Brunswick, New Jersey
}

\begin{abstract}
OBJECTIVE Moyamoya disease (MMD) is an intracranial steno-occlusive pathology characterized by progressive narrowing of proximal large vessels, including the terminal internal carotid arteries (ICAs), middle cerebral arteries, or anterior cerebral arteries. Named for the "puff of smoke" appearance of the anomalous vascularization visualized on cerebral angiography, MMD lacks a well-defined etiology, although significant insights have been made, including the identification of a susceptibility gene, RNF213, in humans with the disease. A limitation to advancing the understanding and treatment of MMD has been the lack of experimental animal models that authentically reflect the clinical pathogenesis. In an effort to analyze characteristics of currently available models and identify strategies for future model generation, the authors performed a scoping review of experimental animal models that have been used to study MMD.
\end{abstract}

METHODS A systematic search of PubMed, Web of Science, and Scopus was performed to identify articles describing animal models used to study MMD. Additional articles were identified via citation searching. Study selection and data extraction were performed by two independent reviewers based on defined inclusion and exclusion criteria.

RESULTS A total of 44 articles were included for full-text review. The methods used to generate these animal models were broadly classified as surgical $(n=25,56.8 \%)$, immunological $(n=7,15.9 \%)$, genetic $(n=6,13.6 \%)$, or a combination $(n=6,13.6 \%)$. Surgical models typically involved permanent ligation of one or both of the common carotid arteries or ICAs to produce chronic cerebral hypoperfusion. Genetic models utilized known MMD or cerebrovascular diseaserelated genes, such as RNF213 or ACTA2, to induce heritable cerebral vasculopathy. Finally, immunological models attempted to induce vasculitis-type pathology by recapitulating the inflammatory milieu thought to underlie MMD.

CONCLUSIONS Models generated for MMD have involved three general approaches: surgical, immunological, and genetic. Although each reflects a key aspect of MMD pathogenesis, the failure of any individual model to recapitulate the development, progression, and consequences of the disease underscores the importance of future work in developing a multietiology model.

https://thejns.org/doi/abs/10.3171/2021.6.FOCUS21284

KEYWORDS moyamoya disease; cerebral ischemia; animal models; encephalomyosynangiosis; indirect revascularization; RNF213

$\mathrm{M}$ OYAMOYA disease (MMD) is an intracranial steno-occlusive disease characterized by anomalous collateral vascularization, resembling a cloud of smoke on angiography, for which the disease was named moyamoya (Japanese for "puff of smoke")., ${ }^{1,2}$ MMD is now recognized to occur across the globe, with a predilection for East Asian populations, and to exhibit a bimodal distribution with peak incidences in the 1st and 4th decades. ${ }^{3-6}$ In children, the disease most commonly manifests with ischemic symptoms (i.e., focal neurologi- cal deficit), while adults tend to present with intracranial hemorrhage and signs of mass effect (e.g., headache and papilledema) $)^{7,8}$

Although still poorly understood, recent elucidations into the pathogenesis of MMD have advanced our knowledge of disease etiology and progression. ${ }^{9}$ Notably, genetic studies have identified ring finger protein 213 (RNF213) as a susceptibility gene mutated in $95 \%$ and $73 \%$ of familial and nonfamilial cases, respectively. ${ }^{10,11}$ Interestingly, a c. $14576 \mathrm{G}>\mathrm{A}$ variant has been isolated in which homozygos-

ABBREVIATIONS CBF = cerebral blood flow; CCA = common carotid artery; EMS = encephalomyosynangiosis; ICA = internal carotid artery; MCA = middle cerebral artery; $M D P=$ muramyl dipeptide; $M M D=$ moyamoya disease; $R N F 213=$ ring finger protein $213 ; \mathrm{TGI}=$ transient global ischemia; tMCAO = transient MCA occlusion .

SUBMITTED May 1, 2021. ACCEPTED June 18, 2021.

INCLUDE WHEN CITING DOI: 10.3171/2021.6.FOCUS21284.

${ }^{*}$ M.S.R. and O.A. contributed equally to this work. 
ity confers earlier onset, more severe symptoms, and worse prognosis. ${ }^{12}$ In addition to pervasive genetic factors, postmortem studies have demonstrated conserved histopathological changes, including folding/duplication of the elastic lamina, fibrocellular thickening of the intima with invasion of inflammatory cells, necrotic cell accumulation, and proliferation of vascular smooth muscle cells, together resulting in intraluminal narrowing of afflicted vessels. ${ }^{7,9,13,14}$

Advances made in defining pathophysiological aspects of MMD have set the foundation for the development of animal models to recapitulate the genetic, immunological, and ischemic mechanisms. Surgical models utilize mechanical occlusion or narrowing of extracranial and/ or intracranial vasculature to replicate stenosis and accompanying cerebral ischemia. ${ }^{15,16}$ Immunological models attempt to induce a "vasculitic" syndrome to reproduce the morphological changes observed in the intracranial vasculature of patients with MMD. ${ }^{17,18}$ Finally, with the identification of the RNF213 susceptibility gene, various knockout, knock-in, or knockdown genetic models have been generated to study its impact on vasculogenesis, angiogenesis, and remodeling..$^{11,19-21}$ While these models reproduce the disparate aspects of MMD independently, no model exists that satisfactorily combines genetic predisposition, immunologically mediated vasculopathy, and chronic ischemia. This lack of an in vivo model has hindered advancement of the field..$^{22}$ In an effort to analyze characteristics of currently available models and identify strategies for future model generation, we have performed a scoping review of experimental animal models that have been used to study MMD.

\section{Methods}

A scoping review was performed according to Preferred Reporting Items for Systematic Reviews and MetaAnalyses (PRISMA) 2020 guidelines; the protocol for this review has not been previously registered. Queries of the PubMed, Scopus, and Web of Science databases were performed on April 7, 2021, for various combinations of key terms ("moyamoya," "animal," "model," "rat," "mouse," "cat," "rabbit," and "pig"), with additional articles identified via citation searching. Screening was performed by two independent reviewers (M.S.R. and O.A.). Articles included for full-text analysis were those using animal models to explicitly address MMD pathogenesis (i.e., genetics, inflammation, or chronic cerebral ischemia) and/ or to evaluate experimental treatments relevant to MMD (e.g., encephalomyosynangiosis [EMS] and gene therapy). Articles were excluded if the analysis of the animal model did not explicitly evaluate the cerebrovasculature (i.e., not directly relevant to MMD) or if no full text was available. Data regarding animal model species, techniques, relevant histopathology, objectives and outcomes, assessment methods, and mortality were collected from full texts.

\section{Results}

Our search returned a total of 846 articles and 2 additional articles were identified via citation searching. Removal of duplicates resulted in 714 unique articles of which 56 articles were included for full-text screening.
Twelve articles were excluded for failure to report findings related to the cerebrovasculature. In total, 44 articles satisfied the inclusion and exclusion criteria and were reviewed for data collection (Fig. 1).

Animal models described in each study were categorized as surgical, immunological, or genetic based on the methods used to recapitulate MMD pathogenesis. These represented $56.8 \%(\mathrm{n}=25), 15.9 \%(\mathrm{n}=7)$, and $13.6 \%(\mathrm{n}$ $=6$ ) of the articles, respectively. Models that incorporated both genetic and surgical strategies were described in 5 $(11.4 \%)$ articles, while only 1 model (2.3\%) combined genetic and immunological techniques. Of the articles employing surgical techniques for animal model generation (n $=30$ ), suture ligation of the common carotid artery (CCA; $46.7 \%, \mathrm{n}=14$ ) or internal carotid artery (ICA; 20.0\%, $\mathrm{n}=$ 6 ) was the most prevalent approach for inducing chronic cerebral ischemia. Nineteen of the $25(76 \%)$ surgery-only models aimed to evaluate experimental treatments such as indirect revascularization (i.e., EMS; 68.4\%, $\mathrm{n}=13$ ). Models involving immunological techniques $(\mathrm{n}=8)$ included serum sickness $(37.5 \%, \mathrm{n}=3)$, systemic or local injection of inflammatory stimuli $(50 \%, \mathrm{n}=4)$, and administration of infectious material $(12.5 \%, \mathrm{n}=1)$. Finally, the most common genetic approach $(\mathrm{n}=12)$ was mutation of the MMD susceptibility gene RNF213 $(75.0 \%, \mathrm{n}=9)$ or other angiogenesis/vascular factors. A variety of species have been used to generate animal models of MMD. Murine species, including both mice $(\mathrm{n}=18)$ and rats $(\mathrm{n}=20)$, accounted for $86.4 \%$ of all included studies and $96.7 \%(\mathrm{n}=$ 29) of those utilizing surgical techniques.

\section{Discussion}

Establishing a model that authentically reflects the pathogenesis/consequences of MMD has been elusive. In this scoping review, we identified three general approaches utilized to develop various animal models: 1) surgical production of hypoperfusion/ischemia; 2) immunological initiation of cerebral vasculitis; and 3) genetic induction of cerebral vasculopathy. These strategies and the individual models are discussed in detail below and summarized in Fig. 2. Though this scoping review did not directly evaluate quality of evidence and included studies of various designs, it provides important insight into general strategies for generating MMD animal models.

\section{Surgical Models of MMD}

Chronic cerebral ischemia is the hallmark consequence of MMD due to the progressive steno-occlusion of proximal intracranial arteries. ${ }^{23}$ Due to the paucity of animal models that authentically mimic moyamoya pathogenesis, surgical models of chronic hypoperfusion have been the mainstay for uncovering the brain's response to ischemia and evaluating the effectiveness of surgical revascularization. The ischemic microenvironment of moyamoya has been simulated via surgical ligation or stenosis of the CCAs or ICAs in mice, rats, and pigs. Multiple paradigms have been described including unilateral, concurrent bilateral, and staged bilateral ligation. These techniques provide standardized, reproducible models by which experimental therapies can be evaluated. Indeed, interventions such as 


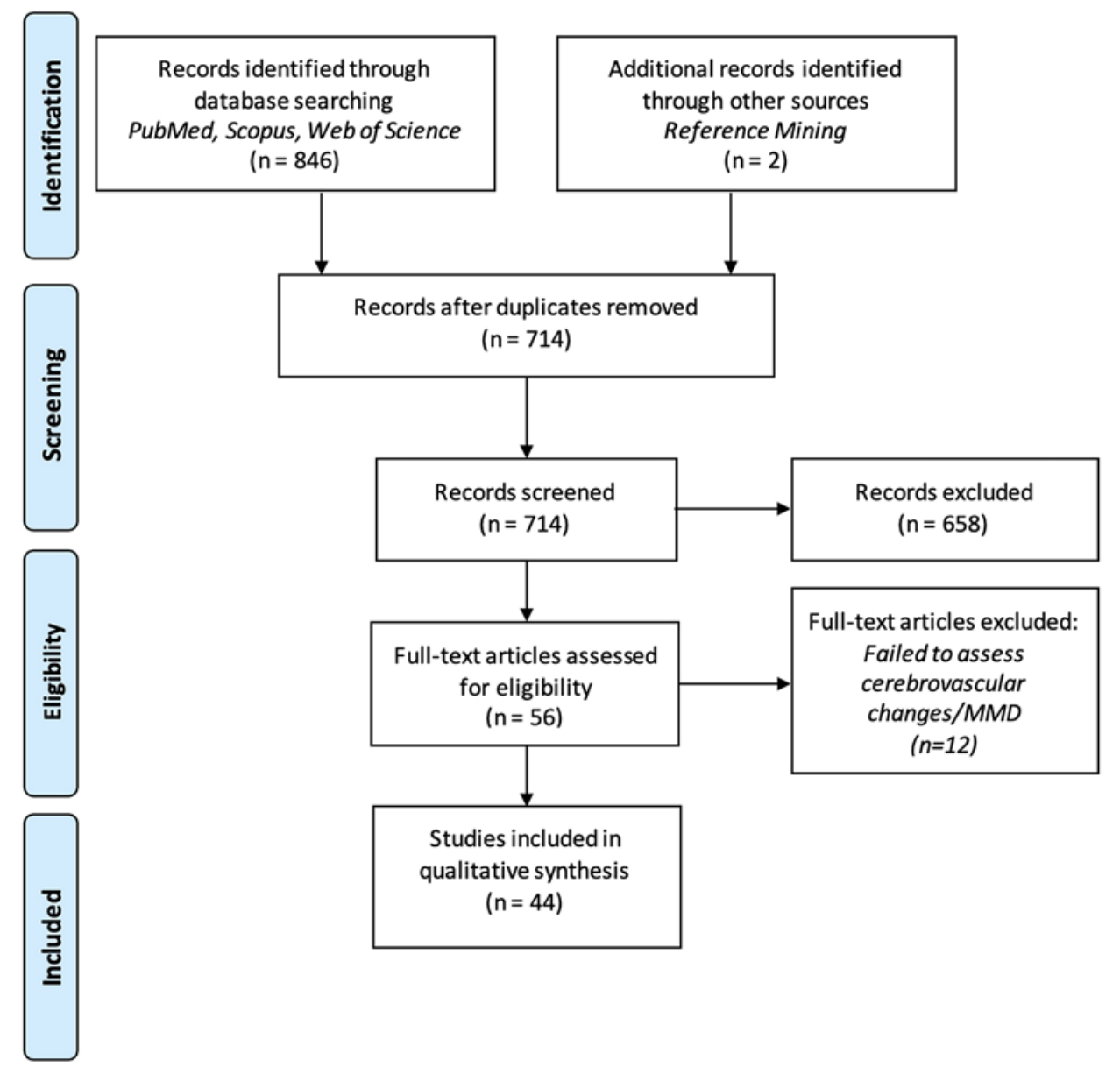

FIG. 1. PRISMA flow diagram of record identification, screening, and inclusion.

EMS, growth factor (i.e., VEGF and bFGF) application, and genetic therapies were tested in over three-quarters of the articles employing surgical models. Furthermore, surgically induced ischemia has provided insight into the role of MMD-related genetic factors (i.e., RNF213) in vascular remodeling,,$^{20,24,25}$ angiogenesis,,$^{21,26}$ and inflammation. ${ }^{24}$

Despite the benefits of surgical models, several limitations exist. 1) They fail to recapitulate genetic/inflammatory mechanisms and are, therefore, not ideal for evaluating MMD pathogenesis. 2) By producing a sudden reduction in cerebral blood flow (CBF), surgical models produce acute deficit and are associated with high mortality, which is uncommon among patients with MMD. ${ }^{27}$ 3) The technically challenging aspects institute a learning curve that must be overcome prior to achieving satisfactory reproducibility. Individual surgical models developed for the study of ischemic consequences and/or treatment are described in detail below and summarized in Table 1.

\section{Carotid Artery Occlusion or Stenosis}

Our analysis identified two-vessel occlusion of the bilateral CCAs as the most common method for induction of cerebral ischemia. Microsurgically, the CCAs are exposed through a straight midline incision and isolated from adjacent sympathetic/vagus nerves. ${ }^{28-36}$ Occlusion is typically achieved by ligation with 3-0 (rats) to 6-0 (mice) silk or nylon sutures proximal to the carotid bifurcation. In one report, the CCAs were ligated with suture on each end prior to being transected..$^{35}$ Bilateral CCA ligation results in a large, immediate decline in CBF that is detectable by laser Doppler flowmetry, laser speckle imaging, and MRI. Generally, an immediate decline in CBF to approximately $30 \%$ of the baseline is indicative of successful bilateral occlusion..$^{37,38}$ Expectedly, this is associated with a large degree of acute deficit, including postprocedural mortality up to $63 \%$, and is not reflective of the chronic decline observed in MMD. ${ }^{36}$ Two-vessel occlusion adaptations, such as staged ligation, have been described to counter these issues. ${ }^{15,37}$ While a grossly similar reduction in CBF (average of $24.18 \%$ of baseline) has been observed, this modification affords a more progressive decline that may mitigate acute deficit. Unilateral occlusion of the CCA has also been described..$^{20,24,25,39,40}$ In the only study reporting on mortality, no animals were found to have died as a result of the surgery, suggesting a potential protective effect of unilateral over bilateral CCA occlusion. ${ }^{20}$ Finally, both unilateral and bilateral ligations of the ICAs are associated with more modest reductions in CBF to approximately $70 \%$ to $80 \%$ of the baseline. ${ }^{16,41-45}$ Such modest reduction following ICA occlusion may represent compensation due 


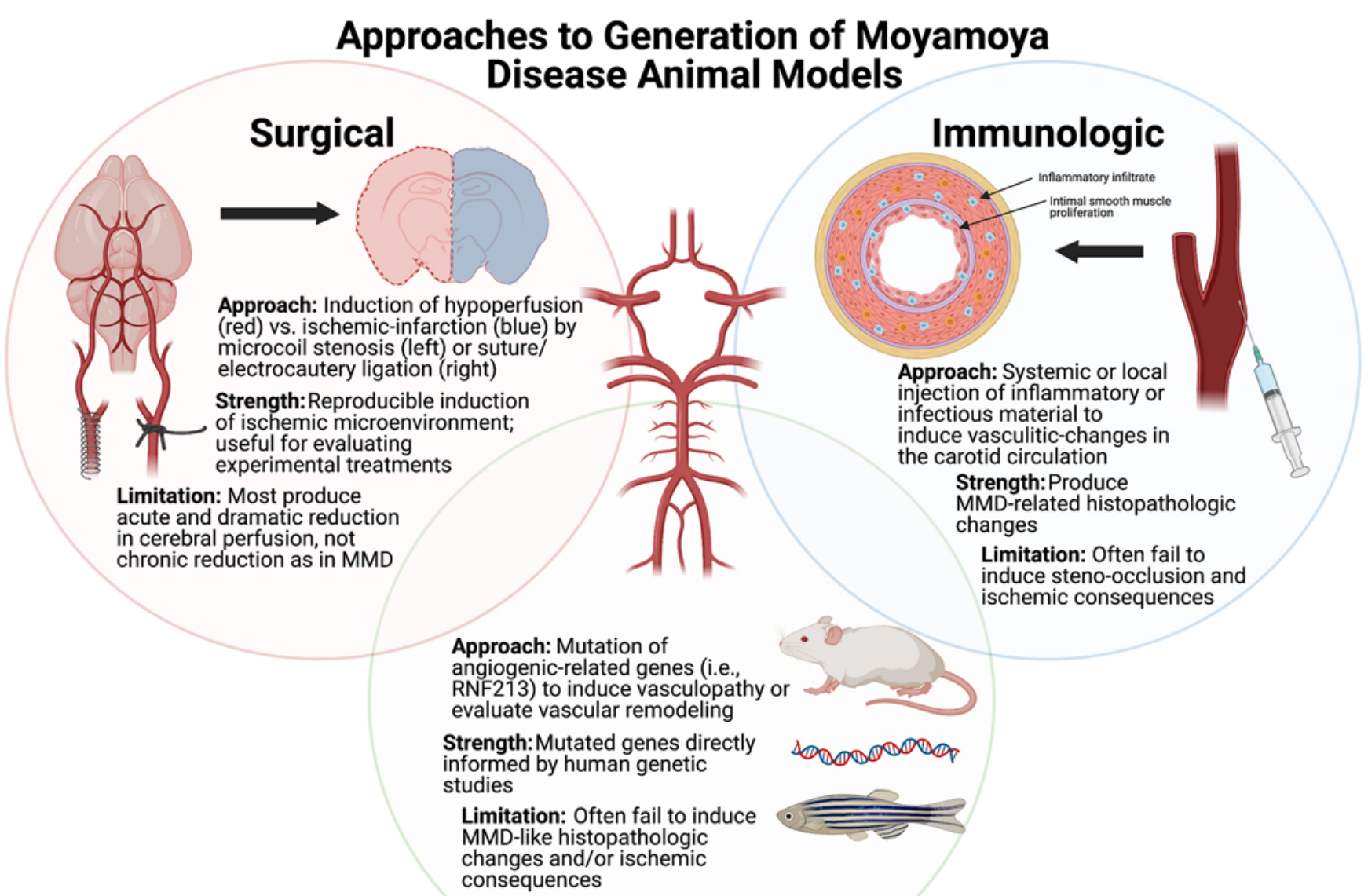

\section{Genetic}

FIG. 2. Summary of approaches for generating MMD animal models. Made in $\mathrm{CB}$ BioRender - biorender.com.

to vascular remodeling and collateral formation. For example, extracranial-to-intracranial anastomoses have been demonstrated via the pterygopalatine artery following ICA and middle cerebral artery (MCA) occlusion. ${ }^{46,47}$ Notably, variation in collateral anatomy across rodent strains might also impact the degree of hypoperfusion and should be considered in future models. ${ }^{48}$

More recently, carotid artery stenosis models have been reported for the study of MMD and/or vascular dementia, as they permit more discrete control of the level of preserved perfusion. This may be accomplished by external application of select-sized microcoils (internal diameter between 0.16 and $0.18 \mathrm{~mm}$ ) to the microsurgically exposed CCAs or ICAs. ${ }^{26,49,50}$ When applied to the CCA, this approach is associated with a moderate reduction in $\mathrm{CBF}$ (between $38.4 \%$ and $49.3 \%$ ) and no mortality. ${ }^{26,49}$ However, for the ICA stenosis model, 2 of the $6(33.3 \%)$ mice died after the procedure for unclear reasons..$^{51}$ A novel strategy, termed modified CCA occlusion, was developed by Mansour et al. ${ }^{74}$ in which Sprague-Dawley rats underwent left CCA suture ligation and right CCA stenosis. The stenosis was produced by tying a suture around the vessel and an adjacent 29-gauge needle to prevent the knot from com- pletely occluding the right CCA. This was associated with a low rate of mortality (2.3\%) and mild to moderate reduction in CBF (occlusion side 63\% $\pm 1.6 \%$; stenosis side $73 \%$ $\pm 2.1 \%) 1$ hour after surgery. $21,52,53,74$

\section{Transient Ischemia}

While chronic hypoperfusion most closely replicates the MMD microenvironment, transient ischemia has also been used to investigate the cellular and molecular response to hypoxia. Two distinct strategies of transient ischemia were identified in our analysis. The first was the transient MCA occlusion (tMCAO) model, classically used to induce acute ischemic stroke in rodents, ${ }^{21,52,53}$ which involves threading a blunt, silicone-coated, monofilament suture from the origin of the external carotid artery through the ICA until resistance is felt, indicating occlusion of the origin of the MCA. Removal of the monofilament after 1 hour permits restoration of blood flow. There is a clear discrepancy between the transient/focal nature of this model and MMD pathophysiology, which involves progressive, often bilateral/global, steno-occlusion. The anatomical discrepancy is partially absolved by the transient global ischemia (TGI) model, in which hypoperfu- 


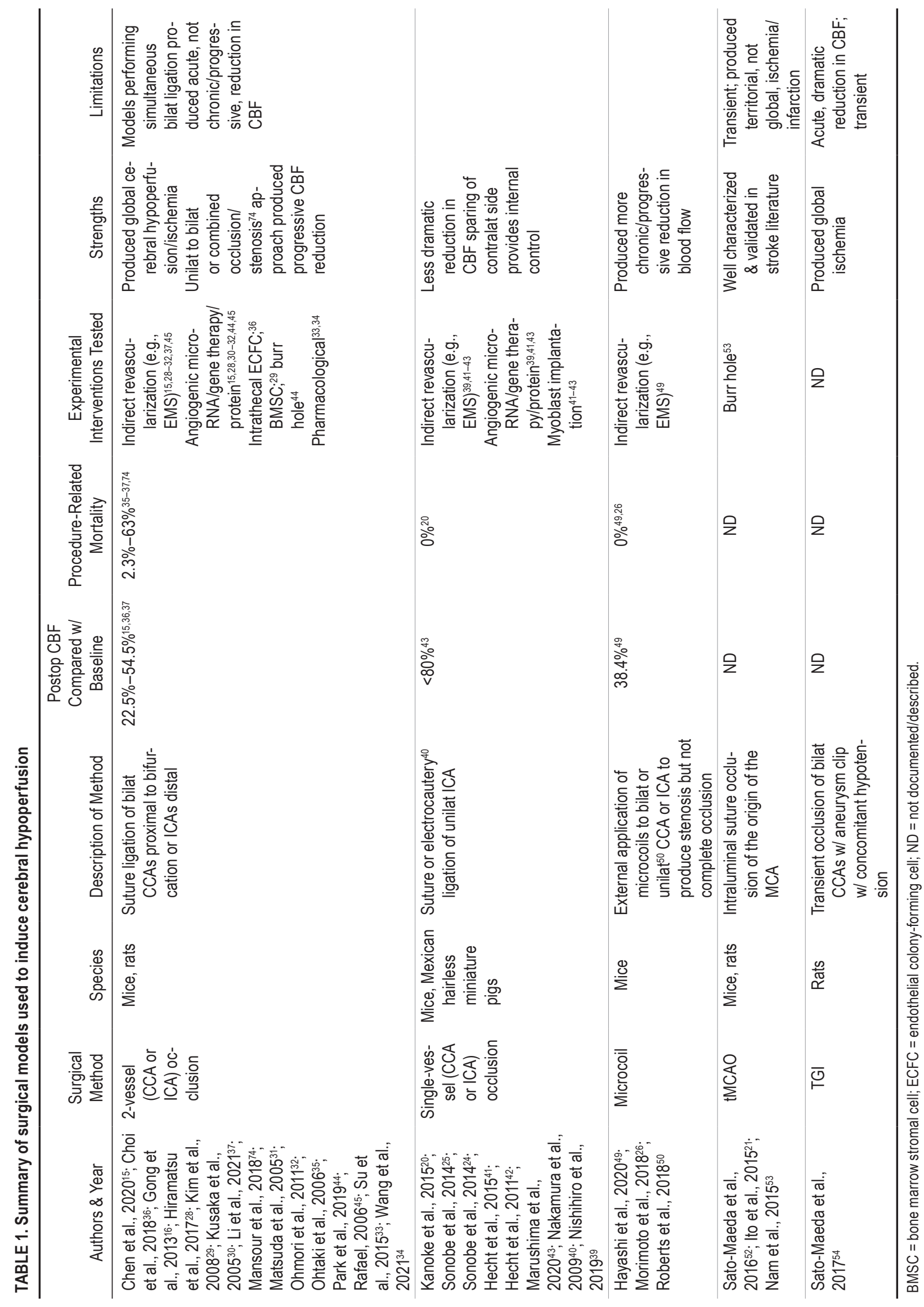


TABLE 2. Summary of immunological models used to produce an MMD phenotype

\begin{tabular}{|c|c|c|c|c|}
\hline Authors \& Year & Species & Immunological Method & Histopathological Findings & Limitations \\
\hline $\begin{array}{l}\text { Kasai et al., } \\
1982^{57}\end{array}$ & $\begin{array}{c}\text { Mongrel } \\
\text { dogs }\end{array}$ & $\begin{array}{l}\text { Serum sickness: multiple } \\
\text { intravenous or subcutaneous } \\
\text { injections of horse or cat } \\
\text { serum }\end{array}$ & $\begin{array}{l}\text { Intimal thickening, elastic lamina folding/ } \\
\text { tortuosity, medial thinning/necrosis; } \\
\text { localization of changes to terminal ICA, } \\
\text { consistent w/ MMD }\end{array}$ & $\begin{array}{l}\text { Failed to identify immune complexes } \\
\text { in vessel wall; financial \& ethical } \\
\text { concerns regarding use of canine } \\
\text { models }\end{array}$ \\
\hline $\begin{array}{l}\text { Ezura et al., } \\
1992^{60}\end{array}$ & Rabbits & $\begin{array}{l}\text { Serum sickness: presensitiza- } \\
\text { tion via intravenous injection } \\
\text { of horse serum followed by } \\
\text { intracisternal injection of } \\
\text { horse serum \& anti-horse } \\
\text { serum antibodies }\end{array}$ & $\begin{array}{l}\text { Inflammatory infiltrate w/in adventitia of intra- } \\
\text { cranial (cerebral \& meningeal) vessels }\end{array}$ & $\begin{array}{l}\text { Pathology limited to adventitia; no } \\
\text { changes in intima or media }\end{array}$ \\
\hline $\begin{array}{l}\text { Rao et al., } \\
2003^{61}\end{array}$ & Rabbits & $\begin{array}{l}\text { Serum sickness: injected } \\
\text { rabbits intravenously or near } \\
\text { terminal carotid artery for up } \\
\text { to } 1 \mathrm{yr}\end{array}$ & $\begin{array}{l}\text { Intimal hyperplasia, elastic degeneration, } \\
\text { deposition of immunoglobulins w/in termi- } \\
\text { nal ICA; extension of hyperplastic smooth } \\
\text { muscle cells through internal elastic } \\
\text { disruptions resulting in luminal stenosis }\end{array}$ & Long-term inoculation \& maintenance \\
\hline $\begin{array}{l}\text { Yamada et } \\
\text { al., } 1997^{17}\end{array}$ & $\begin{array}{l}\text { Sprague- } \\
\text { Dawley } \\
\text { rats }\end{array}$ & $\begin{array}{l}\text { Infectious: injection of rats w/ } \\
P . \text { acnes in area surrounding } \\
\text { bilat carotid bifurcations }\end{array}$ & $\begin{array}{l}\text { Coarse duplication \& disruption of the inter- } \\
\text { nal elastic lamina }\end{array}$ & $\begin{array}{l}\text { No intimal thickening, medial } \\
\text { thinning/necrosis, or occlusive } \\
\text { stenosis }\end{array}$ \\
\hline $\begin{array}{l}\text { Suzuki et al., } \\
1987^{63}\end{array}$ & Wistar rats & $\begin{array}{l}\text { Inflammatory: intravenous or } \\
\text { intrathecal injection of MDP }\end{array}$ & $\begin{array}{l}\text { Disruption of internal elastic lamina, medial } \\
\text { necrosis, predominantly w/in terminal ICA }\end{array}$ & $\begin{array}{l}\text { Failed to produce intimal thickening } \\
\text { \& stenosis }\end{array}$ \\
\hline $\begin{array}{l}\text { Kamata et al., } \\
2003^{18}\end{array}$ & Cats & \multirow{2}{*}{$\begin{array}{l}\text { Inflammatory: immunoembolic } \\
\text { injection of MDP in a rod- } \\
\text { shaped lactic acid/glycolic } \\
\text { acid (50:50) copolymer } \\
\text { following sensitization w/ } \\
\text { intravenous injection of MDP }\end{array}$} & \multirow[t]{2}{*}{ Duplication of internal elastic lamina } & \multirow{2}{*}{$\begin{array}{l}\text { Mild intimal thickening was only } \\
\text { present in the cats; no stenosis, } \\
\text { collateral vessel development on } \\
\text { angiography }\end{array}$} \\
\hline $\begin{array}{l}\text { Terai et al., } \\
2003^{62}\end{array}$ & Monkeys & & & \\
\hline
\end{tabular}

sion is achieved through both temporary (5-minute) occlusion of the bilateral CCAs and maintenance of systemic hypotension. ${ }^{54}$ Using both the tMCAO and TGI models, Sato-Maeda et al. demonstrated significant induction of RNF213 expression in neurons within ischemic tissue. ${ }^{52,54}$ However, the transient nature of these models limits the generalizability of these findings to MMD since they fail to capture the complex neovascularization and vascular remodeling that accompany chronic hypoperfusion.

Histopathological analysis has focused on evaluating neovascularization and/or angiogenesis occurring secondary to cerebral ischemia. This often involves quantitative assessment of microvessel density or size via immunohistochemistry against vessel markers (CD31/PECAM, VWF, RECA-1) ${ }^{32,39,44}$ Neovascularization and angiogenesis are evident in the ischemic cerebrum, and quantitative measurements can be used to compare the extent of revascularization across experimental treatments or conditions. Together with functional assays, such as evaluation of vascular permeability with Evans blue dye, these techniques can also identify formation of small, thin-walled collateral vessels consistent with MMD. ${ }^{44}$

\section{Immunological Models of MMD}

While predisposition to MMD is linked to genetic factors (i.e., RNF213), the low penetrance of the phenotype in humans and failure of mutant animals to recapitulate the clinical phenotype suggest an important role for en- vironmental triggers. ${ }^{17,55,56}$ Indeed, infectious and/or inflammatory insults are postulated to be inciting or amplifying pathogenic mechanisms. This is based, in part, on histopathological evidence confirming the presence of leukocytes and proliferating smooth muscle cells within the thickened intima of stenotic intracranial arteries from patients with MMD..$^{14}$ In fact, MMD has been considered a variant of vasculitic syndrome and/or autoimmune disease. ${ }^{57-59}$ This has led to the development of several immunologically based animal models that aimed to recapitulate the complex inflammatory milieu of MMD (Table 2).

\section{Serum Sickness Models}

Based on the high prevalence of chronic inflammation (e.g., chronic tonsilitis) and histopathological findings resemblant of polyarteritis nodosa in patients with MMD, Kasai et al. set out to demonstrate an immunological etiology of MMD in mongrel dogs. ${ }^{57}$ Their model induced serum sickness via injection of horse or cat serum, which would generate circulating immune complexes that could deposit within intracranial vasculature. Although histopathology failed to demonstrate the presence of immune complexes within these vessels, arterial specimens demonstrated intimal thickening, elastic lamina tortuosity, and medial thinning/necrosis most drastic within the ICA terminus. While this study asserted a likely role for inflammation in MMD, failure to identify intracranial immune complexes limits its pathogenic implications. Moreover, financial, labor, and 
ethical limitations pertaining to the use of canine models limit replicability. Ten years later, Ezura et al. sought to characterize cerebral arterial lesions within a rabbit model of serum sickness. ${ }^{60}$ Their first trial involved sensitization via intravenous injection of heterogeneous serum followed by induction of type III hypersensitivity 3 weeks later with a second injection of horse serum. Although systemic vasculitis was appreciated, no such changes occurred in the cerebral circulation. A second trial was conducted in which sensitization and induction occurred as in the first, but with an added intracisternal injection of anti-horse serum antibodies or horse serum itself. Inflammatory infiltrate and immune complexes were observed in the adventitia of cerebral arteries from both groups, although it was more marked in rabbits receiving antibodies. Finally, their third trial involved simultaneous intravenous injection of antigen and intracisternal injection of antibody without prior sensitization. Notably, inflammatory infiltrate that subsided within 5 days was observed, suggesting that interaction between circulating antigen and antibody, rather than deposition of immune complexes, may be involved in MMD. A similar model involving chronic inoculation of rabbits with horse serum for up to 1 year produced intimal hyperplasia, elastic degeneration, and deposition of immunoglobulins within the terminal ICA. Moreover, extension of hyperplastic smooth muscles through the internal disruptions resulted in luminal stenosis. ${ }^{61}$ The ability of this model to induce characteristic histopathological changes, in addition to arterial stenosis, make it a promising approach for recapitulating clinically relevant pathology. However, the requirement for long-term maintenance limits its ability to become widely adopted.

\section{Propionibacterium acnes Infection Model}

Supporting a role for bacterial infection as an inciting inflammatory factor in MMD, Yamada et al. found that $69.4 \%$ of patients with MMD had elevated levels of either anti-Propionibacterium acnes, anti-Mycoplasma pneumoniae, anti-streptokinase, anti-streptolysin, anti-toxoplasma antibodies, or C-reactive protein. ${ }^{17}$ To investigate a causal role, $P$. acnes, a generally nonpathogenic bacterium, was injected bilaterally around the carotid bifurcation in 7-day-old rats for 4 weeks. Coarse duplication and disruption of the internal elastic lamina, similar to that observed in MMD and the mongrel dog model, was present in intracranial ICA specimens. However, intimal thickening, medial thinning/necrosis, and stenosis were not appreciated. ${ }^{17}$ While this model appears to recapitulate certain aspects of MMD, it fails to induce the progressive steno-occlusion and ischemia that are the hallmark consequence.

\section{Injection of Proinflammatory Materials}

Systemic or local injection of proinflammatory materials has been used to model MMD in cats, ${ }^{18}$ monkeys, ${ }^{62}$ rats, ${ }^{63}$ and transgenic $\left(R N F 213^{-/-}\right)$mice. ${ }^{19}$ The material used, $N$-acetylmuramyl-L-alanyl-D-isoglutamine (muramyl dipeptide [MDP]), is the structural unit of the bacterial cell wall, which acts as an adjuvant for evoking an immune response. ${ }^{64}$ The first model, described by Suzuki et al. in 1987, utilized intravenous or intrathecal injection of MDP and identified MMD-like pathological changes, namely, disruption of the internal elastic lamina and medial degeneration, predominantly within the terminal ICA. ${ }^{63}$ However, this model failed to induce intimal thickening and stenosis. Intravascular immunoembolic injections of MDP in a rod-shaped lactic acid/glycolic acid copolymer were utilized to induce moyamoya-like pathology in monkeys and cats following sensitization via intravenous injection. ${ }^{18,62}$ While both demonstrated pathological changes in the terminal ICA, including duplication of the internal elastic lamina, mild intimal thickening was present only in the feline model. Moreover, angiography prior to the animal being euthanized revealed no significant stenosis or collateral vessel development. The lack of collateral vessels in cats, despite the presence of intimal thickening, might have been due to the rich supply of blood from the external carotid artery to the feline brain. Finally, a combined immunological-genetic model was reported by Kanoke et al. in 2016, in which $R N F 23^{-1-}$ mice were administered adjuvants, including MDP, to determine if an immunological reaction is an influential secondary insult in the development of MMD. ${ }^{19}$ Implicating $R N F 213$ in an immunomodulatory role, knockout mice displayed a decreased ratio of regulatory $\mathrm{T}$ cells. However, the immunological stimulation failed to induce characteristic findings of MMD on gross inspection of the circle of Willis and by MRA of the cerebrovasculature.

\section{Genetic Models of MMD}

While genetic factors have been implicated in MMD for decades, $R N F 213$ was not identified as a susceptibility gene until 2011..$^{10,11}$ This presented an incredible opportunity to study the disease at the molecular level through biochemical and molecular biological approaches. Moreover, the discovery brought with it the promise of generating transgenic animal models of MMD, which could propel understanding of pathogenesis and accelerate development of novel treatment strategies. The types of genetic models developed are summarized in Table 3.

\section{RNF213 Mutant Animals}

The development of a transgenic $R N F 213$ mutant was presented simultaneously with the identification of the gene by Liu et al. in 2011.11 Utilizing morpholino technology against two zebrafish $R N F 213$ genes (RNF213- $\alpha$ and $-\beta)$, the group generated the first knockdown animals in an effort to observe the physiological function of $R N F 213$. Knockdown of $R N F 213-\alpha$, but not $R N F 213-\beta$, resulted in inappropriate vasculogenesis including altered vessel sprouting, particularly within the developing head. This evidence, which first implicated $R N F 213$ as a regulator of intracranial angiogenesis, has been more recently confirmed by transcription activator-like effector nuclease (TALEN)-mediated generation of $R N F 213-\alpha$ mutant zebrafish that exhibit similar abnormalities in angiogenesis and sprouting. ${ }^{65}$ Zebrafish are incredibly useful model organisms given their unique developmental characteristics (e.g., external fertilization permitting direct observation of embryogenesis) and their relative ease of maintenance.

Despite these breakthrough findings, the role of RNF213 in MMD is elusive; it remains unclear if diseaserelated mutations represent gain- or loss-of-function in- 
TABLE 3. Summary of genetic approaches to producing an MMD phenotype

\begin{tabular}{|c|c|c|}
\hline Authors \& Year & Model & Relevant Histopathological/Angiographic Findings \\
\hline $\begin{array}{l}\text { Liu et al., } \\
2011^{11}\end{array}$ & $\begin{array}{l}\text { Zebrafish RNF213 knock- } \\
\text { down model: application } \\
\text { of morpholinos against } \\
\text { zebrafish RNF213 ortho- } \\
\text { logs (RNF213- } \alpha \text { \& }-\beta \text { ) to } \\
\text { knock down expression }\end{array}$ & $\begin{array}{l}\text { Inappropriate vasculogenesis, including altered vessel sprouting, particularly in head where multiple } \\
\text { abnormal vessels were observed sprouting from optic vessels at } 60-72 \mathrm{hrs} \text { postfertilization. }\end{array}$ \\
\hline $\begin{array}{l}\text { Wen et al., } \\
2016^{65}\end{array}$ & $\begin{array}{l}\text { Zebrafish RNF213 knockout } \\
\text { model: generated by } \\
\text { TALEN technique }\end{array}$ & $\begin{array}{l}\text { Inappropriate vasculogenesis in intersegmental vessels \& cranial secondary vessels. Defective mor- } \\
\text { phogenesis \& vascular tube formation by endothelial cells. Reduced circulation through abnormal } \\
\text { sprouting vessels of head \& neck revealed by microangiography. Lower erythrocyte velocity through } \\
\text { dorsal aorta. }\end{array}$ \\
\hline $\begin{array}{l}\text { Sonobe et } \\
\text { al., } 2014^{25} \text {; } \\
\text { Sonobe et } \\
\text { al., } 2014^{24} \text {; } \\
\text { Kanoke et al., } \\
2016^{19} \text {; Ito et } \\
\text { al., } 2015^{21} \text {; } \\
\text { Morimoto et } \\
\text { al., } 2018^{26}\end{array}$ & $\begin{array}{l}\text { Mouse } R N F 213 \text { knockout } \\
\text { model }\left(R N F 213^{--}\right)\end{array}$ & 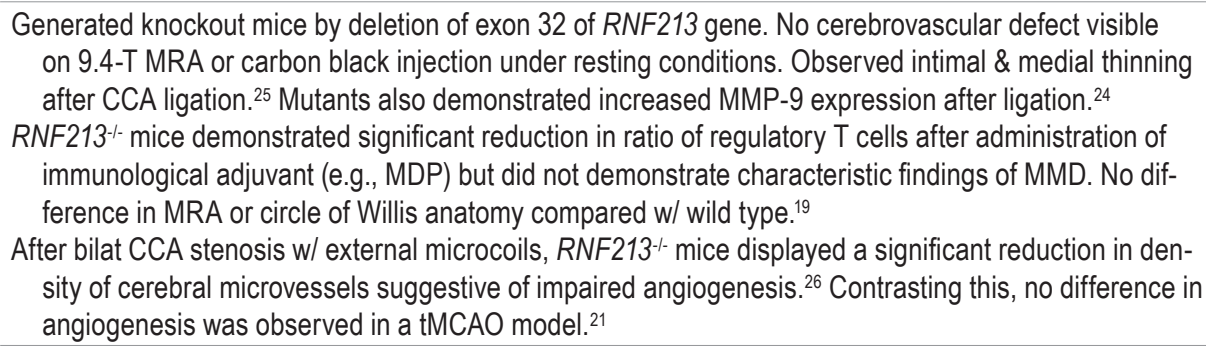 \\
\hline $\begin{array}{l}\text { Kanoke et al., } \\
2015^{20}\end{array}$ & $\begin{array}{l}\text { Mouse RNF213-R4828K } \\
\text { knock-in model: gener- } \\
\text { ated mice that express } \\
\text { R4828K missense muta- } \\
\text { tion, ortholog of human } \\
\text { mutant } R 4859 \mathrm{~K}\end{array}$ & $\begin{array}{l}\text { No cerebrovascular defect visible on 9.4-T MRA or carbon black injection under resting conditions. No } \\
\text { difference in thickness of intracranial vasculature or in vascular remodeling following CCA ligation } \\
\text { btwn mutant \& wild-type animals. }\end{array}$ \\
\hline $\begin{array}{l}\text { Kobayashi et } \\
\text { al., } 2015^{67}\end{array}$ & $\begin{array}{l}\text { Mouse RNF213-R4757K } \\
\text { overexpression model: } \\
\text { generated mice that } \\
\text { overexpress } R 4757 \mathrm{~K} \\
\text { variant of } R N F 213, \text { or- } \\
\text { tholog of human mutant } \\
\text { R4810K in endothelial or } \\
\text { smooth muscle cells }\end{array}$ & $\begin{array}{l}\text { Angiogenesis was not induced in mice overexpressing } R 4757 \mathrm{~K} \text { w/in endothelial cells after hypoxia } \\
\text { (induced via } 8 \% \text { oxygen chamber). However, angiogenesis was present in wild-type, endothelial } \\
\text { cell-specific overexpression, \& knockout mice. No evidence of stenotic lesions, moyamoya vessels, } \\
\text { or cerebral infarction. }\end{array}$ \\
\hline $\begin{array}{l}\text { Starosolski et } \\
\text { al., } 2015^{71}\end{array}$ & $\begin{array}{l}\text { Mouse ACTA2 knockout } \\
\text { model }\left(A C T A 2^{--}\right)\end{array}$ & $\begin{array}{l}\text { Narrowing \& straightening of large vessels w/in circle of Willis identified by a novel imaging approach } \\
\text { combining ultra-high-resolution CT \& a long-circulating contrast agent. }\end{array}$ \\
\hline $\begin{array}{l}\text { Ren et al., } \\
2021^{73}\end{array}$ & $\begin{array}{l}\text { Mouse NEO1 knockout } \\
\text { model }\left(N E O 1^{-l}\right)\end{array}$ & $\begin{array}{l}N E O 1^{-1-} \& \text { astrocyte-specific NEO1 deficiency resulted in small, leaky, thin blood vessels w/in the cere- } \\
\text { bral cortex \& cognitive impairment. }\end{array}$ \\
\hline $\begin{array}{l}\text { Hyacinth et al., } \\
2019^{70}\end{array}$ & $\begin{array}{l}\text { Mouse HbSS-Townes } \\
\text { humanized sickle cell } \\
\text { model }\end{array}$ & $\begin{array}{l}\text { Identified shortened, tortuous, \& dilated cerebral capillaries w/ a higher rate of occlusive events using } \\
\text { in vivo 2-photon microscopy. Postmortem immunohistochemistry confirmed presence of cortical } \\
\text { microinfarcts. }\end{array}$ \\
\hline
\end{tabular}

TALEN = transcription activator-like effector nuclease.

sults. RNF213 knockout $\left(R N F 213^{-/-}\right)$mice generated by Cre/loxP-mediated deletion of exon 32 demonstrated no gross, histological, or radiological evidence of MMDlike pathology. ${ }^{25}$ Similarly, knock-in mice expressing orthologs of human MMD-related polymorphisms have failed to demonstrate clinically relevant histopathological changes. ${ }^{20}$ However, after ligation of the CCA, temporary thinning of the intimal and medial layers was observed in the knockout animals. ${ }^{25}$ This suggests that inciting factors, such as inflammation, infection, radiation, or ischemia, must be coupled with the genetic lesion in order to induce the MMD-like phenotype. In fact, intraperitoneal injection of proinflammatory factors (TNF- $\alpha$ and IFN- $\gamma$ ) activates the transcription of $R N F 213$ and appears to link inflammation with angiogenic pathways. ${ }^{66}$ Further studies combining RNF213-deficient or knock-in mice and surgical approaches, such as tMCAO or CCA ligation, continue to demonstrate a unique role for the gene in MMD-related processes including vascular remodeling, ${ }^{20,24,25}$ angiogenesis, $^{21,26,67}$ and inflammation. ${ }^{24}$

\section{Other Transgenic Models}

Additional genes implicated in human cerebrovascular diseases and MMD include ACTA2, which encodes $\alpha$-smooth muscle actin, and NEO1, which encodes a transmembrane receptor or coreceptor for multiple ligands, 
such as netrins, repulsive guidance molecules, and bone morphogenetic proteins. ${ }^{68-70}$ Utilizing a novel ultra-highresolution in vivo $\mathrm{CT}$ approach with a long circulating liposome-iodinated contrast agent, Starosolski et al. identified narrowing of the circle of Willis and abnormal straightening of large vessels in ACTA2 mutant mice similar to the clinical pattern observed in MMD. ${ }^{71,72}$ NEOI-deficient mice have also recently been shown to have moyamoyalike vasculopathy, particularly the development of small, leaky, thin blood vessels within the cerebral cortex. ${ }^{73}$ Interestingly, this phenotype was observed with astrocytespecific deletion of NEOI, suggesting that MMD may involve dysregulated signaling between cellular components of the neurovascular unit. The continued identification of susceptibility genes for MMD will provide novel genetic targets for the generation of animal models. Future work employing intersectional genetic approaches, where multiple genes can be efficiently deleted or mutated, may help the research community overcome the barrier posed by lack of authentic models of this unique disease.

\section{Conclusions}

In this review, we identified several surgical, immunological, and genetic approaches that have been used to generate experimental animal models of MMD. While surgical models can produce ischemic consequences comparable with MMD, they fail to recapitulate the chronic, progressive pattern of ischemia. Although genetic and immunological models take an etiological approach at inducing vasculopathy, they have heretofore been limited in generating histopathological changes (e.g., arterial stenosis) and consequences (e.g., hypoperfusion and ischemia). There remains a critical need for the development of novel animal models that accurately reflect the pathophysiology and histopathology of MMD. The multifactorial etiology of MMD supported by the existing literature, therefore, insists that successful animal models reflect a combination of genetic susceptibility and environmental insults.

\section{References}

1. Guey S, Tournier-Lasserve E, Hervé D, Kossorotoff M. Moyamoya disease and syndromes: from genetics to clinical management. Appl Clin Genet. 2015;8:49-68.

2. Suzuki J, Takaku A, Fukasawa H. D-19. Cerebrovascular "moyamoya" disease among the Japanese, on study of a autopsy case. Neurol Med Chir (Tokyo). 1966;8:269-270.

3. Nishimoto A, Takeuchi S. Abnormal cerebrovascular network related to the internal cartoid arteries. J Neurosurg. 1968;29(3):255-260.

4. Kudo T. Spontaneous occlusion of the circle of Willis. A disease apparently confined to Japanese. Neurology. 1968;18(5): 485-496.

5. Acker G, Goerdes S, Schneider UC, Schmiedek P, Czabanka M, Vajkoczy P. Distinct clinical and radiographic characteristics of moyamoya disease amongst European Caucasians. Eur J Neurol. 2015;22(6):1012-1017.

6. Uchino K, Johnston SC, Becker KJ, Tirschwell DL. Moyamoya disease in Washington State and California. Neurology. 2005;65(6):956-958.

7. Research Committee on the Pathology and Treatment of Spontaneous Occlusion of the Circle of Willis. Guidelines for diagnosis and treatment of moyamoya disease (spontaneous occlusion of the circle of Willis). Neurol Med Chir (Tokyo). 2012;52(5):245-266.

8. Kainth D, Chaudhry SA, Kainth H, Suri FK, Qureshi AI. Epidemiological and clinical features of moyamoya disease in the USA. Neuroepidemiology. 2013;40(4):282-287.

9. Houkin K, Ito M, Sugiyama T, Shichinohe H, Nakayama N, Kazumata K, Kuroda S. Review of past research and current concepts on the etiology of moyamoya disease. Neurol Med Chir (Tokyo). 2012;52(5):267-277.

10. Kamada F, Aoki Y, Narisawa A, Abe Y, Komatsuzaki S, Kikuchi A, et al. A genome-wide association study identifies RNF213 as the first Moyamoya disease gene. J Hum Genet. 2011;56(1):34-40.

11. Liu W, Morito D, Takashima S, Mineharu Y, Kobayashi H, Hitomi T, et al. Identification of RNF213 as a susceptibility gene for moyamoya disease and its possible role in vascular development. PLoS One. 2011;6(7):e22542.

12. Miyatake S, Touho H, Miyake N, Ohba C, Doi H, Saitsu H, et al. Sibling cases of moyamoya disease having homozygous and heterozygous c. $14576 \mathrm{G}>\mathrm{A}$ variant in RNF213 showed varying clinical course and severity. J Hum Genet. 2012; 57(12):804-806.

13. Oka K, Yamashita M, Sadoshima S, Tanaka K. Cerebral haemorrhage in Moyamoya disease at autopsy. Virchows Arch A Pathol Anat Histol. 1981;392(3):247-261.

14. Masuda J, Ogata J, Yutani C. Smooth muscle cell proliferation and localization of macrophages and $\mathrm{T}$ cells in the occlusive intracranial major arteries in moyamoya disease. Stroke. 1993;24(12):1960-1967.

15. Chen C, Ling C, Gong J, Li C, Zhang L, Gao S, et al. Increasing the expression of microRNA-126-5p in the temporal muscle can promote angiogenesis in the chronically ischemic brains of rats subjected to two-vessel occlusion plus encephalo-myosynangiosis. Aging (Albany NY). 2020;12(13):13234-13254.

16. Gong H, Shu L, Xu H, Chen B, Mao R, Zhang F, Wang Y. Bilateral internal carotid arteries ligation temporary impairs brain vasculaturev in young rats. Auton Neurosci. 2013;173(12):39-44

17. Yamada H, Deguchi K, Tanigawara T, Takenaka K, Nishimura Y, Shinoda J, et al. The relationship between moyamoya disease and bacterial infection. Clin Neurol Neurosurg. 1997; 99(suppl 2):S221-S224.

18. Kamata I, Terai Y, Ohmoto T. Attempt to establish an experimental animal model of moyamoya disease using immunoembolic material-histological changes of the arterial wall resulting from immunological reaction in cats. Acta Med Okayama. 2003;57(3):143-150.

19. Kanoke A, Fujimura M, Niizuma K, Fujimura T, Kakizaki A, Ito A, et al. Temporal profile of magnetic resonance angiography and decreased ratio of regulatory $\mathrm{T}$ cells after immunological adjuvant administration to mice lacking RNF213, a susceptibility gene for moyamoya disease. Brain Res. 2016; 1642:1-9.

20. Kanoke A, Fujimura M, Niizuma K, Ito A, Sakata H, SatoMaeda M, et al. Temporal profile of the vascular anatomy evaluated by 9.4-tesla magnetic resonance angiography and histological analysis in mice with the R4859K mutation of $R N F 213$, the susceptibility gene for moyamoya disease. Brain Res. 2015;1624:497-505.

21. Ito A, Fujimura M, Niizuma K, Kanoke A, Sakata H, MoritaFujimura Y, et al. Enhanced post-ischemic angiogenesis in mice lacking $R N F 213$; a susceptibility gene for moyamoya disease. Brain Res. 2015;1594:310-320.

22. Hamauchi S, Shichinohe H, Houkin K. Review of past and present research on experimental models of moyamoya disease. Brain Circ. 2015;1(1):88-96.

23. Huang S, Guo ZN, Shi M, Yang Y, Rao M. Etiology and pathogenesis of Moyamoya Disease: An update on disease prevalence. Int J Stroke. 2017;12(3):246-253. 
24. Sonobe S, Fujimura M, Niizuma K, Fujimura T, Furudate $\mathrm{S}$, Nishijima $\mathrm{Y}$, et al. Increased vascular MMP-9 in mice lacking RNF213: moyamoya disease susceptibility gene. Neuroreport. 2014;25(18):1442-1446.

25. Sonobe S, Fujimura M, Niizuma K, Nishijima Y, Ito A, Shimizu $\mathrm{H}$, et al. Temporal profile of the vascular anatomy evaluated by 9.4-T magnetic resonance angiography and histopathological analysis in mice lacking RNF213: a susceptibility gene for moyamoya disease. Brain Res. 2014;1552:64-71.

26. Morimoto T, Enmi JI, Hattori Y, Iguchi S, Saito S, Harada $\mathrm{KH}$, et al. Dysregulation of RNF213 promotes cerebral hypoperfusion. Sci Rep. 2018;8(1):3607.

27. Wang Z, Fan J, Wang J, Li Y, Duan D, Du G, Wang Q. Chronic cerebral hypoperfusion induces long-lasting cognitive deficits accompanied by long-term hippocampal silent synapses increase in rats. Behav Brain Res. 2016;301:243-252.

28. Hiramatsu M, Hishikawa T, Tokunaga K, Kidoya H, Nishihiro S, Haruma J, et al. Combined gene therapy with vascular endothelial growth factor plus apelin in a chronic cerebral hypoperfusion model in rats. J Neurosurg. 2017;127(3):679686.

29. Kim HS, Lee HJ, Yeu IS, Yi JS, Yang JH, Lee IW. The neovascularization effect of bone marrow stromal cells in temporal muscle after encephalomyosynangiosis in chronic cerebral ischemic rats. J Korean Neurosurg Soc. 2008;44(4): 249-255.

30. Kusaka N, Sugiu K, Tokunaga K, Katsumata A, Nishida A, Namba K, et al. Enhanced brain angiogenesis in chronic cerebral hypoperfusion after administration of plasmid human vascular endothelial growth factor in combination with indirect vasoreconstructive surgery. J Neurosurg. 2005; 103(5):882-890.

31. Matsuda T, Abe T, Wu JL, Fujiki M, Kobayashi H. Hypoxiainducible factor- $1 \alpha$ DNA induced angiogenesis in a rat cerebral ischemia model. Neurol Res. 2005;27(5):503-508.

32. Ohmori Y, Morioka M, Kaku Y, Kawano T, Kuratsu J. Granulocyte colony-stimulating factor enhances the angiogenetic effect of indirect bypass surgery for chronic cerebral hypoperfusion in a rat model. Neurosurgery. 2011;68(5):1372-1379.

33. Su SH, Wu YF, Lin Q, Yu F, Hai J. Cannabinoid receptor agonist WIN55,212-2 and fatty acid amide hydrolase inhibitor URB597 suppress chronic cerebral hypoperfusioninduced neuronal apoptosis by inhibiting c-Jun N-terminal kinase signaling. Neuroscience. 2015;301:563-575.

34. Wang DP, Lin Q, Kang K, Wu YF, Su SH, Hai J. Preservation of spatial memory and neuroprotection by the fatty acid amide hydrolase inhibitor URB597 in a rat model of vascular dementia. Ann Transl Med. 2021;9(3):228.

35. Ohtaki H, Fujimoto T, Sato T, Kishimoto K, Fujimoto M, Moriya M, Shioda S. Progressive expression of vascular endothelial growth factor (VEGF) and angiogenesis after chronic ischemic hypoperfusion in rat. Acta Neurochir Suppl. 2006;96:283-287.

36. Choi SA, Chong S, Kwak PA, Moon YJ, Jangra A, Phi JH, et al. Impaired functional recovery of endothelial colonyforming cells from moyamoya disease in a chronic cerebral hypoperfusion rat model. J Neurosurg Pediatr. 2018;23(2): 204-213.

37. Li W, Wei L, Wang B, Gao S, Huang T, Li Z, et al. The trend of indirect anastomosis formation in a 2-vessel occlusion plus encephalo-myo-synangiosis rat model. Ann Transl Med. 2021;9(1):19.

38. Jiang T, Zhang L, Pan X, Zheng H, Chen X, Li L, et al. Physical exercise improves cognitive function together with microglia phenotype modulation and remyelination in chronic cerebral hypoperfusion. Front Cell Neurosci. 2017;11:404.

39. Nishihiro S, Hishikawa T, Hiramatsu M, Kidani N, Takahashi Y, Murai S, et al. High-mobility group Box-1-induced angiogenesis after indirect bypass surgery in a chronic cere- bral hypoperfusion model. Neuromolecular Med. 2019;21(4): 391-400.

40. Nakamura M, Imai H, Konno K, Kubota C, Seki K, Puentes $\mathrm{S}$, et al. Experimental investigation of encephalomyosynangiosis using gyrencephalic brain of the miniature pig: histopathological evaluation of dynamic reconstruction of vessels for functional anastomosis. Laboratory investigation. J Neurosurg Pediatr. 2009;3(6):488-495.

41. Hecht N, Marushima A, Nieminen M, Kremenetskaia I, von Degenfeld G, Woitzik J, Vajkoczy P. Myoblast-mediated gene therapy improves functional collateralization in chronic cerebral hypoperfusion. Stroke. 2015;46(1):203-211.

42. Hecht N, Peña-Tapia P, Vinci M, von Degenfeld G, Woitzik J, Vajkoczy P. Myoblast-mediated gene therapy via encephalomyosynangiosis--a novel strategy for local delivery of gene products to the brain surface. J Neurosci Methods. 2011; 201(1):61-66.

43. Marushima A, Nieminen M, Kremenetskaia I, Gianni-Barrera R, Woitzik J, von Degenfeld G, et al. Balanced singlevector co-delivery of VEGF/PDGF-BB improves functional collateralization in chronic cerebral ischemia. J Cereb Blood Flow Metab. 2020;40(2):404-419.

44. Park GH, Shin HS, Choi ES, Yoon BS, Choi MH, Lee SJ, et al. Cranial burr hole with erythropoietin administration induces reverse arteriogenesis from the enriched extracranium. Neurobiol Dis. 2019;132:104538.

45. Rafael H. Chronic brain ischemia and revascularization. $J$ Neurosurg. 2006;105(2):339-341.

46. Tamaki M, Kidoguchi K, Mizobe T, Koyama J, Kondoh T, Sakurai T, et al. Carotid artery occlusion and collateral circulation in C57Black/6J mice detected by synchrotron radiation microangiography. Kobe J Med Sci. 2006;52(5):111-118.

47. Wang J, Lin X, Mu Z, Shen F, Zhang L, Xie Q, et al. Rapamycin increases collateral circulation in rodent brain after focal ischemia as detected by multiple modality dynamic imaging. Theranostics. 2019;9(17):4923-4934.

48. Oliff HS, Coyle P, Weber E. Rat strain and vendor differences in collateral anastomoses. J Cereb Blood Flow Metab. 1997; 17(5):571-576.

49. Hayashi T, Yamamoto S, Hamashima T, Mori H, Sasahara M, Kuroda S. Critical role of platelet-derived growth factor- $\alpha$ in angiogenesis after indirect bypass in a murine moyamoya disease model. J Neurosurg. 2020;134(5):1535-1543.

50. Roberts JM, Maniskas ME, Fraser JF, Bix GJ. Internal carotid artery stenosis: a novel surgical model for moyamoya syndrome. PLoS One. 2018;13(1):e0191312.

51. Roberts J, Maniskas M, Bix G, et al. A novel mouse surgical model for moyamoya. J Cereb Blood Flow Metab. 2017;37(1 Suppl):31.

52. Sato-Maeda M, Fujimura M, Kanoke A, Morita-Fujimura Y, Niizuma K, Tominaga T. Transient middle cerebral artery occlusion in mice induces neuronal expression of RNF213, a susceptibility gene for moyamoya disease. Brain Res. 2016; 1630:50-55

53. Nam TK, Park SW, Park YS, Kwon JT, Min BK, Hwang SN. Role of a burr hole and calvarial bone marrow-derived stem cells in the ischemic rat brain: a possible mechanism for the efficacy of multiple burr hole surgery in moyamoya disease. $J$ Korean Neurosurg Soc. 2015;58(3):167-174.

54. Sato-Maeda M, Fujimura M, Rashad S, Morita-Fujimura Y, Niizuma K, Sakata H, et al. Transient global cerebral ischemia induces $R N F 213$, a moyamoya disease susceptibility gene, in vulnerable neurons of the rat hippocampus CA1 subregion and ischemic cortex. J Stroke Cerebrovasc Dis. 2017;26(9):1904-1911.

55. Roder C, Nayak NR, Khan N, Tatagiba M, Inoue I, Krischek B. Genetics of Moyamoya disease. J Hum Genet. 2010;55(11): 711-716.

56. Ullrich NJ, Robertson R, Kinnamon DD, Scott RM, Kieran 
MW, Turner CD, et al. Moyamoya following cranial irradiation for primary brain tumors in children. Neurology. 2007; 68(12):932-938.

57. Kasai N, Fujiwara S, Kodama N, Yonemitsu T, Suzuki J. The experimental study on causal genesis of moyamoya disease - correlation with immunological reaction and sympathetic nerve influence for vascular changes. Article in Japanese. No Shinkei Geka. 1982;10(3):251-261.

58. Chen JB, Liu Y, Zhou LX, Sun H, He M, You C. Prevalence of autoimmune disease in moyamoya disease patients in Western Chinese population. J Neurol Sci. 2015;351(1-2):184-186.

59. Chen JB, Liu Y, Zhou LX, Sun H, He M, You C. Increased prevalence of autoimmune disease in patients with unilateral compared with bilateral moyamoya disease. J Neurosurg. 2016;124(5):1215-1220.

60. Ezura M, Fujiwara S, Nose M, Yoshimoto T, Kyogoku M. Attempts to induce immune-mediated cerebral arterial injury for an experimental model of moyamoya disease. Childs Nerv Syst. 1992;8(5):263-267.

61. Rao M, Zhang H, Liu Q, Zhang S, Hu L, Deng F. Clinical and experimental pathology of Moyamoya disease. Chin Med $J$ (Engl). 2003;116(12):1845-1849.

62. Terai Y, Kamata I, Ohmoto T. Experimental study of the pathogenesis of moyamoya disease: histological changes in the arterial wall caused by immunological reactions in monkeys. Acta Med Okayama. 2003;57(5):241-248.

63. Suzuki J, Yonemitsu T, Ezura M, Fujiwara S. Experimental Study on Etiology of Moyamoya Disease: Effects of Bacterial Cell Wall on Cerebral Artery. Annual Report (1986) of the Research Commmittee on Spontaneous Occlusion of the Circle of Willis (Moyamoya Disease) of the Ministry of Health and Welfare, Japan. Ministry of Health and Welfare, Japan; 1987.

64. Nagai Y, Akiyama K, Suzuki K, Kotani S, Watanabe Y, Shimono T, et al. Minimum structural requirements for encephalitogen and for adjuvant in the induction of experimental allergic encephalomyelitis. Cell Immunol. 1978;35(1):158-167.

65. Wen J, Sun X, Chen H, Liu H, Lai R, Li J, et al. Mutation of rnf $213 a$ by TALEN causes abnormal angiogenesis and circulation defects in zebrafish. Brain Res. 2016;1644:70-78.

66. Ohkubo K, Sakai Y, Inoue H, Akamine S, Ishizaki Y, Matsushita Y, et al. Moyamoya disease susceptibility gene RNF213 links inflammatory and angiogenic signals in endothelial cells. Sci Rep. 2015;5:13191.

67. Kobayashi H, Matsuda Y, Hitomi T, Okuda H, Shioi H, Matsuda T, et al. Biochemical and functional characterization of RNF213 (Mysterin) R4810K, a susceptibility mutation of moyamoya disease, in angiogenesis in vitro and in vivo. $\mathrm{J} \mathrm{Am}$ Heart Assoc. 2015;4(7):e002146.

68. Kang HS, Moon YJ, Kim YY, Park WY, Park AK, Wang KC, et al. Smooth-muscle progenitor cells isolated from patients with moyamoya disease: novel experimental cell model. $J$ Neurosurg. 2014;120(2):415-425.
69. Guo DC, Papke CL, Tran-Fadulu V, Regalado ES, Avidan N, Johnson RJ, et al. Mutations in smooth muscle alpha-actin (ACTA2) cause coronary artery disease, stroke, and Moyamoya disease, along with thoracic aortic disease. Am J Hum Genet. 2009;84(5):617-627.

70. Hyacinth HI, Sugihara CL, Spencer TL, Archer DR, Shih AY. Higher prevalence of spontaneous cerebral vasculopathy and cerebral infarcts in a mouse model of sickle cell disease. J Cereb Blood Flow Metab. 2019;39(2):342-351.

71. Starosolski Z, Villamizar CA, Rendon D, Paldino MJ, Milewicz DM, Ghaghada KB, Annapragada AV. Ultra high-resolution in vivo computed tomography imaging of mouse cerebrovasculature using a long circulating blood pool contrast agent. Sci Rep. 2015;5:10178.

72. Starosolski Z, Wright J, Milewicz D, et al. Gender-dependent differences in the cerebrovascular system in wildtype mice and cerebrovascular lesions in a mouse model of moyamoya disease. Stroke. 2017;48(Suppl 1):AWP282.

73. Ren X, Yao LL, Pan JX, Zhang JS, Mei L, Wang YG, Xiong WC. Linking cortical astrocytic neogenin deficiency to the development of Moyamoya disease-like vasculopathy. Neurobiol Dis. 2021;154:105339.

74. Mansour A, Niizuma K, Rashad S, Sumiyoshi A, Ryoke R, Endo H, et al. A refined model of chronic cerebral hypoperfusion resulting in cognitive impairment and a low mortality rate in rats. J Neurosurg. 2018;131(3):892-902.

\section{Disclosures}

The authors report no conflict of interest concerning the materials or methods used in this study or the findings specified in this paper.

\section{Author Contributions}

Conception and design: Rallo. Acquisition of data: Rallo, Akel, Gurram. Analysis and interpretation of data: Rallo, Akel. Drafting the article: Rallo, Akel, Gurram. Critically revising the article: Sun, Rallo, Akel. Reviewed submitted version of manuscript: all authors. Approved the final version of the manuscript on behalf of all authors: Sun. Statistical analysis: Rallo. Administrative/technical/material support: Sun. Study supervision: Sun.

\section{Correspondence}

Hai Sun: Rutgers Robert Wood Johnson Medical School, New Brunswick, NJ.hs925@rwjms.rutgers.edu. 